\title{
Study on Flexible Employment Policies and the Linkage Mechanism of Shaanxi Private College Graduates
}

\author{
Zhong Shu ${ }^{1, a}$ \\ ${ }^{1}$ Xi'an International University, Xi'an, Shaanxi, 710077 \\ ${ }^{a}$ email
}

Keywords: The Employment Situation; Private Colleges Factors, Policy

\begin{abstract}
Since entering the new era, with the prosperity of the social market economy, knowledge of the use of scientific information showing a "big bang" trend has become even more intense competition for talent. The employment situation of the large number of college graduates face become particularly severe. Especially for teachers in all aspects, resources, students, etc. are not a predominance of private schools, it is a challenge and pressure. In this context and the environment, how to help students out of the plight of employment, we need to make adjustments in strategy, innovation in services. From the Employment of the past two years, private colleges and universities in Shaanxi, discusses policies to promote employment and linkage mechanism, to think and summarize effective strategies to solve the problem from the study.
\end{abstract}

\section{Introduction}

As early as during the 2000s, a huge shift occurred in the country's education. By a handful of elite education, it gradually transition to the majority of public education. Large contingent of graduates, university enrollment around are in full swing. The rise of private schools and more people have the opportunity "into College" in. At the same time, how to "go social" has become difficult. This is related to students' personal growth and future, but also affects the reputation of the school and survival fate of private schools. Society and the State has been the focus of this investment with a high degree of concern, universities have combined their own development characteristics have worked out a series of measures to improve the practical ability of university students. According to the data show a slight improvement in the employment status quo, however, private universities are still many problems, especially in the various departments to mobilize all forces and mechanisms to address the joint establishment also was not perfect, not only to improve the employment rate from settings, reinforcing learning skills courses begin unilaterally, but also should be more from the perspective of other aspects of implementation of the strategy.

\section{The Status of Employment of University Graduates in Shaanxi Private Universities}

Statistical data from the point of view of the overall size of Private Colleges in Shaanxi provinces is higher than the other, some institutions the number of indicators of living in the country's first location in the steady development of the situation in which there are 17 undergraduate level, college level there are 10, number of people, a wide range of campus [1]. However, it was found that a comprehensive comparison, on the one hand the employment rate of graduates generally lag behind in public universities, some of the more popular professional employment rate does not even reach 20\%; on the other hand, professional and job mismatch contradictions and oversupply more prominent contradictions.

\section{The Reason of Shaanxi Private College Graduates Employment Difficulties Affect}

From the perspective of school factors. Since most of the self-management of private colleges and universities are educational institutions of their investments, in terms of students will have a wide variety of problems. Mainly reflected in these points: First, the low visibility. Running short history of private schools, lack of experience, low social status, still can not get public acceptance and 
recognition; second, weak teaching. Teachers and the device does not dominate curriculum unreasonable, poor teaching standards, will lead to lack of students' abilities and qualities, lack of competitiveness. There are blind expansion of college enrollment, students draw, copying foreign education model, an exclusive focus on technology led to its narrow student employment; Third, employment guidance policy is wrong. Run Colleges and Universities Young qualifications, all aspects of the policy is still in perfect stage in the career guidance that only a lack of capital investment, but no more co-operation and employment information can be provided to students in reference selection; moreover, no established specialized employment services and regulations to guide the student is not in place, not targeted. Most stay in the national policy interpretation, analysis of situation in the province, to convey information on employment and so on. For example, some lack the necessary job skills training; some do not depart from the accurate positioning of school, out of school characteristics, etc. [2].

From the perspective of the individual factors. Graduates Employment and the main students' awareness and perceptions of psychological factors. First, the traditional values of the affected community, easy to "unrealistic expectations" as the pursuit of high-paying vocational "excellent learning Shi", etc., and their skills, knowledge does not match; secondly, expectations too high. Just out of the ivory tower of the students, poor frustration, and their own lack of accurate positioning. Originally poor students based private institutions, strong inferiority complex, when faced with the reality of their own expectations formed a huge gap of time, suffered a job interview of "hitting the wall" situation often confused or even negative escape; Finally, the information channel is not smooth. Before employment, does not take the initiative to collect employment information to make a scientific analysis, to develop a comprehensive long-term career planning, can not grasp the needs of the market and understand the market dynamics to be proactive to prepare, did not choose a clear direction and goals in a timely manner, resulting in attention is limited, affecting the smooth employment.

Factors from a social point of view. Objectively, the social and economic development, quality of talent increasingly high demand, private colleges due recognition and influence are not as big as public schools, so students train from here in the course of employment discrimination are vulnerable to outside especially employers hold stereotypes and set in the conduct of recruitment "high threshold" entry qualifications. Many countries, for example, administrative departments and institutions are clearly listed the conditions for the registration of time: either "985", "211 Project" key school; either the academic requirements of the first Masters degree or doctoral these standards. Obviously, these caused to the private college graduates feel "unfair", became their ideal into the industry snagged [3]. From Shaanxi Province developments and geography conditions up analysis, Shaanxi Province, located in the northwest since the economic level compared with other regions in China is relatively backward, limited choice of jobs, while the number of students coming plus accrued in previous years, and this to some We want to reduce the development in the province of employment opportunities for students degree. In addition, the state-level incentives for graduates of private colleges and universities and efforts to implement certain aspects of the supervision is not big enough. Indirect employment for graduates of private colleges had a negative impact.

\section{The Promotion Policy Mechanisms of Shaanxi Flexible Employment}

Faced with the current severe employment situation and market pressures, in order to enhance the employment rate of graduates of private colleges and universities in Shaanxi fundamentally, it should be the policy, institutions, schools and individuals to develop the full range of these angles from solving strategies, improve the employment service in order to establish a flexible joint long-term mechanism.

To improve the school's own strength of the school. Construction of students Employment of new mechanisms and strategies. Improve students 'employment competitiveness and strength of the fundamental, so you can do the following: First, private colleges to conduct courses and adjust the settings based on professional and dynamic market demand for school-related, as far as possible in order to improve students' comprehensive quality as the goal, so that students in all aspects of 
capabilities are to training; second, the school should actively introduce advanced teaching talents from teaching, to provide promotion opportunities for teachers, enhance the excellent construction of teachers; and to multi-building training base for students advance adaptation and exercise their ability, broaden their employment horizons. Third, pay attention to students' innovative creative ability, give full play to the advantages of school discipline.

To increase the students' employment guidance services. First, the school classroom knowledge to change the past simply instill guidance mode, to develop the second classroom to expand the theory and lectures, publicity and other activities combined. To properly guide students to develop career planning, to effectively from their own actual situation, good positioning and should not stay on the surface. This job can be specifically assigned to the school counselor who take one to one counseling and assistance to help students to establish a scientific and rational career outlook and employment outlook, fully stimulate students' employment potential; secondly, the school can hire from the outside of the relevant business units administrator or company, "headhunting" for students to work together to expand workplace skills training, employment and updated dynamic information to students on the employment situation to conduct a comprehensive analysis and prediction to enhance students' awareness of the application and the practical ability of practitioners. Finally, schools should be good at using advanced technology to expand students' personalized employment services. Improve the efficiency of communication between schools and enterprises, in particular, to comply with the call of national policy, such as the face of "highly innovative, entrepreneurial public" era situation, actively encourage and support entrepreneurship graduates from colleges and universities on technical and financial, to get rid of the passive employment problems. You can also set up entrepreneurial society, entrepreneurial design competition was held, the promotion of entrepreneurial experience exchange sessions. In addition, schools should be counseling and career guidance services combine to continuously improve the psychological quality of students, especially positive guidance the students a positive attitude.

On the one hand the government should encourage private universities to independent schools, to be appropriate from the economic support or for running good quality materials on Colleges reward, such as teaching public facilities, particularly bench and training room; should also be implemented Shipping policies to help the introduction of private colleges and universities outstanding teaching workers, and to efforts to promote resources between schools, school experiences, and share employment information; in terms of enrollment, to break the limitations of multiple batches of qualified, private colleges and universities to help absorb more high the students [4]. On the other hand, the state of the employer to implement strict supervision, open to students threshold access to employment, especially "Colleges discrimination" must be reasonable to eliminate; for the establishment of private universities to be strictly controlled, a clear standard of review, technical guidance from the university curriculum and management, for the founder of the more distinctive strength of the strong universities.

College students are the subject of employment, to achieve flexible employment, we must first consolidate their strength, to seize the opportunity of the times, to develop good mental attitude, continue to temper growth. So students should cherish the opportunity to learn in school, especially to clear social demand market for technical capability and practical ability excellent Versatile talents through active participation in school organizations, career guidance class activities to train their own thinking . At the same time pay close attention to market dynamics, identify their strengths and weaknesses, weaknesses, accumulate more experience, summed reflection, pinpoint their employment goals, rational deal with the reality of the ideal relationship with.

In addition, students and other employment-related social departments and personnel should also take measures to actively cooperate to promote employment of graduates. As parents in peacetime to maintain communication and contact with the school, it is necessary to come to have a comprehensive understanding of their children through school grasp feedback and school employment policy, but also take the initiative to offer advice to students, students from families to ease pressures, maintaining optimum employment. In another example, enterprises should change a few paper resume or certificate "to decide their fate," the idea of recruiting, can take the initiative to 
establish partnerships with colleges and universities, and even the corporate culture moved into the campus to students sponsored entrepreneurial activity, may be a recruit to do their own training or internship reserve in advance.

\section{Conclusion}

In conclusion, through comprehensive analysis of the problem of employment of college graduates facing private Shaanxi, explore the influencing factors, to solve the employment problem of contemporary college students have long-term reference. It is worth pondering, employment of graduates of private colleges and universities is not an isolated existence, the need to take "government action, school leadership, social support" strategy system, to establish a joint mechanism to change the severe employment situation.

\section{References}

[1] Huang Yiming. Causes of Private Vocational College Students Employment and Countermeasures [J]. Hua Zhang, 2013 (25): 219-219.

[2] Gao Lijun, Xian Jun, Zhao Li. Research Employment Ability of College Students of Shaanxi private [J]. Heilongjiang Science and Technology Information, 2011 (29): 212-212.

[3] Li Jiajin, Wang Qiaoxia, Xiadian. Analysis and Research Entrepreneurship Survey of Private University Students [J]. Economic Research Guide, 2015 (16): 212-213.

[4] Wang Yan. Situation Investigation network business in Xi'an Private University Students-A Case Study of Xi'an International University Students [J]. Economics, 2015 (8): 229-229. 